Case Report

\title{
Case Reports in Oncological Medicine Myoepithelioma: A New Rearrangement Involving the LPP Locus in a Case of Multiple Bone and Soft Tissue Lesions
}

\author{
Géraldine Pairet, ${ }^{1}$ Gaëlle Tilman, ${ }^{2}$ Rafaël Sciot $\mathbb{D}^{3},{ }^{3}$ Thomas Schubert $\mathbb{D}^{\mathrm{D}},{ }^{4}$ Vasiliki Perlepe, ${ }^{5}$ \\ Hélène A. Poirel $\left(\mathbb{D},{ }^{6}\right.$ and Christine Galant ${ }^{7}$ \\ ${ }^{1}$ Department of Pathology, Cliniques Universitaires Saint-Luc, Brussels, Belgium \\ ${ }^{2}$ Center for Human Genetics, Cliniques Universitaires Saint-Luc-Université catholique de Louvain, Brussels, Belgium \\ ${ }^{3}$ Department of Pathology, Katholieke Universiteit Leuven, Leuven, Belgium \\ ${ }^{4}$ Department of Orthopaedic Surgery, Cliniques Universitaires Saint-Luc, Brussels, Belgium \\ ${ }^{5}$ Department of Medical Imaging, Cliniques Universitaires St-Luc, Brussels, Belgium \\ ${ }^{6}$ Center for Human Genetics, Cliniques Universitaires Saint-Luc and Human Molecular Genetics, de Duve Institute, \\ Université catholique de Louvain, Brussels, Belgium \\ ${ }^{7}$ Department of Pathology, Cliniques Universitaires St-Luc and IREC, Pôle de morphologie MORF, \\ Université Catholique de Louvain, Brussels, Belgium
}

Correspondence should be addressed to Hélène A. Poirel; helene.antoine-poirel@gmx.com

Hélène A. Poirel and Christine Galant contributed equally to this work.

Received 5 October 2017; Accepted 10 December 2017; Published 27 February 2018

Academic Editor: Giovann Tallini

Copyright (c) 2018 Géraldine Pairet et al. This is an open access article distributed under the Creative Commons Attribution License, which permits unrestricted use, distribution, and reproduction in any medium, provided the original work is properly cited.

\begin{abstract}
We report a case of multiple myoepithelioma with synchronous bone and soft tissue tumors, associated with a new genomic alteration of the LPP locus. The lesions occurred in the foot by presenting one lump in the plantar soft tissue, and three lesions were detected in the calcaneus and in the navicular bone. All tumors showed the double immunophenotype of epithelial markers and S100 protein expression. No rearrangement of the EWSR1 and FUS loci was detected as reported in myoepitheliomas. However, molecular karyotyping detected an unbalanced rearrangement of the LPP locus, not involving the HMGA2 locus, which is the most frequent translocation partner observed in benign mesenchymal tumors such as lipomas (of soft tissue as well as parosteal) and pulmonary chondroid hamartoma.
\end{abstract}

\section{Introduction}

Myoepithelial tumors (METs) of soft tissue and bone are rare tumors of uncertain histogenesis. The first deep tumor was described in the retroperitoneum [1], followed by a large series in 1997 including cases in soft tissue [2]. Rare cases in bone are more recently reported, and these lesions tend to occur in the acral region of the lower limbs usually in middle age male patients [3-7]. Axial localization of METs has to be distinguished from chordoma.

Histologically, METs are made of a homogeneous population of myoepithelial cells. They could be considered as a part of a continuum with mixed tumors when ductal differentiation is present. They may harbor chondroid and bone differentiation as observed in classical mixed tumors. The diagnosis of MET requires the coexpression of both epithelial markers and S100 protein $[8,9]$. They share morphological and immunohistochemical features with their counterparts described in skin and salivary gland.

A different genetic pattern distinguishes METs arising in the skin from those in deep soft tissue and bone. EWSR1 (22q12) gene fusions have been detected in half of METs arising in deep soft tissues and in up to $70 \%$ cases of intraosseous MET $[7,10]$. Several partners of EWSR1 are 
described: POU5F1(6p21.33) (16\%), PBX1 (16\%), PBX3, ZNF444, ATF1, KLF17, and NFATC2 [10-16]. The EWSR1POU5F1 more often occurs in children and young adults while the EWSR1-PBX1 occurs in middle-aged adult patients $[11,14]$. The tumors of the first subgroup show a solid or nested growth arrangement of tumor cells showing at least partially a clear appearance of the cytoplasm. The subgroup with EWSR1-PBX1 rearrangement presents a bland sclerotic appearance or clear cell morphology with a diffuse EMA staining. However, none of the EWSR1-rearranged tumors show the presence of ductal or glandular differentiation or cartilage/bone matrix formation [10]. Rearrangement of the FUS(16p11) gene has also been reported in rare cases of MET arising in deep soft tissue as well as in bone $[15,17]$. Two gene partners have been characterized, KLF17 and POU5F1. These FUS-rearranged tumors also lack ductal differentiation [15].

PLAG1 (8q12.1) and HMGA2 (12q14.3) rearrangements are the most common genetic events in pleomorphic adenomas [18]. PLAG1 is also found in MET $[19,20]$. In the study of Anthonescu et al., 3 cutaneous and 10 soft tissue METs (out of a total of 35 tumors) showed the presence of PLAG1 gene rearrangement [19]. All tumors except one showed tubular differentiation, suggesting that MET with tubuloglandular differentiation, called mixed tumors of skin or of soft tissue, are genetically linked to their salivary gland counterpart.

We report an unusual observation in a 52-year-old man of a multifocal MET without obvious ductular differentiation and harboring a new LPP unbalanced rearrangement without EWSR1 and FUS alterations in both soft tissue and bone lesions.

\section{Case Presentation}

A 52-year-old patient complained of pain and swelling of the foot. MRI and plain radiography demonstrated a main lesion in the calcaneus, two others in the navicular bone, and a last one in the plantar soft tissue (Figure 1(a)). The main bone lesion was first investigated by fine needle aspiration. The soft tissue lesion was then resected.

2.1. Pathology. The tumor of the calcaneus measured $4.4 \times 3.4 \mathrm{~cm}$ (Figure $1(\mathrm{~b})$ ), and the other lesions in the medial cuneiform measured $2.2 \times 0.9 \mathrm{~cm}$ (Figure $1(\mathrm{~b})$ ) and $0.5 \mathrm{~mm}$. The one in the soft tissue, resected independently, measured $3.5 \times 2.7 \mathrm{~cm}$. On histology, the different tumors appeared lobulated and contained plasmacytoid cells arranged in lobules and in large cellular sheets, intermixed with areas of fibrous and chondromyxoid stroma positive for alcian blue (Figure 1(d)). These cells showed mild nuclear pleomorphism and some cysts were observed, but no convincing ductular differentiation (Figure 1(e)). Some groups of tumor cells were detected in peripheral vascular spaces, without obvious fibrin but suspicious for vascular emboli (not shown).

Immunohistochemistry demonstrated an intense and diffuse staining of plasmacytoid cells for the broad-spectrum cytokeratin, S100 protein (Figures $1(\mathrm{~g})$ and $1(\mathrm{~h})$ ), and vimentin. A focal staining for GFAP was noticed. EMA was focally positive in the cytoplasm, and a very focal membranous apical staining was also present (Figure 1(f)). There was a diffuse nuclear staining for INI1. Alpha-smooth muscle actin and desmin immunostainings were negative.

These results were in favor the diagnosis of a MET. Based on the multiplicity of localizations, a transtibial amputation was decided by the local multidisciplinary committee. Although lesions were multiple and some pictures were suspicious for vascular emboli, the patient had no recurrence or distant metastasis 2 years later. The last follow-up detected small lung lesions, which remained stable and were considered as aspecific.

2.2. Cytogenetics. Conventional karyotyping detected the same abnormal complex pseudodiploid clone in the soft tissue tumor as in the bone tumor (Figure 2(a)).

FISH experiments were performed to look for rearrangement of genes known to be altered in MET arising in deep soft and bone tissues, EWSR1 and FUS. FISH detected no rearrangement of those loci. Other differential diagnoses were excluded by FISH: extraskeletal myxoid chondrosarcoma (NR4A3) and alveolar soft part sarcoma (TFE3).

Molecular karyotyping detected 2 main deletions on the long arm of chromosome 3 located at 3q22.1-3q26.2 (37Mb) (Figure 2(c)) and 3q27.2-3q28 (3Mb). The latter includes the 5 ' part of the $L P P$ gene, probably the 8 first exons (Figure $2(\mathrm{~d})$ ). Three other interstitial deletions were identified at $8 \mathrm{p} 22(3 \mathrm{Mb})$, $8 \mathrm{q} 23.3(0.3 \mathrm{Mb})$, and $13 \mathrm{q} 14.3(1.4 \mathrm{Mb})$.

FISH experiments with BAC probes confirmed the $3 q 27.3-q 28$ unbalanced rearrangement with the loss of the probe located 5\% centromeric to the LPP locus (Figure 2(b)) but did not detect any rearrangement of the HMGA2 locus which is the most frequently reported partner gene of $L P P$ in different benign mesenchymal tumors.

\section{Discussion}

MET can occur in various sites, but only $9 \%$ of MET occurs in bone. Most of the deep-seated lesions in bone are incidental discoveries. Tumor sites are tibia, ilium, vertebra, maxilla, and sacrum [24-26]. As far as we know, only a cutaneous and subcutaneous MET has been reported in the foot [27]. We described here synchronous tumors in two different bones of the foot and in the soft tissue of a 52-yearold man with no further aggressive evolution.

This observation is also unusual at the genetic level. We did not detect the rearrangement of the EWSR1 and FUS genes classically involved in MET arising in deep soft and bone tissue without ductal differentiation. Instead, a hitherto unreported rearrangement of the LPP locus was found. The LPP gene is known to be rearranged through chromosomal translocations [28]. The most frequent one is the $\mathrm{t}(3 ; 12)(\mathrm{q} 27-\mathrm{q} 28 ; \mathrm{q} 14-\mathrm{q} 15)$, which is recurrent in lipomas (of soft as well as parosteal tumor) and fuses LPP with HMGA2 [29]. This translocation is also described in pulmonary chondroid hamartomas [30] and in one case of soft tissue chondroma [31].

Three other LPP-partner genes have been reported in one case of lipoma, HMGA1(6p21) [32], and in 2 different 


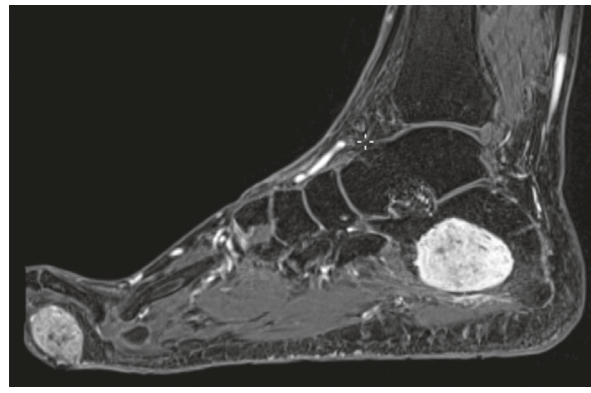

(a)

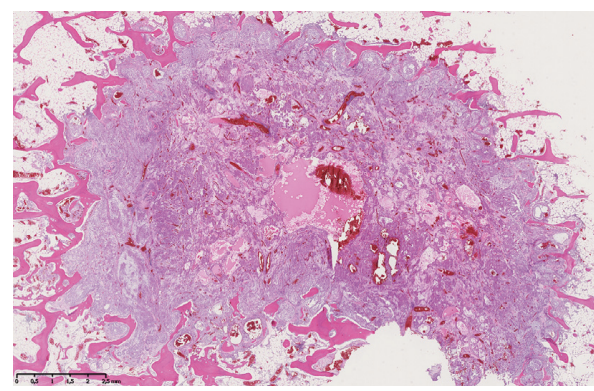

(c)

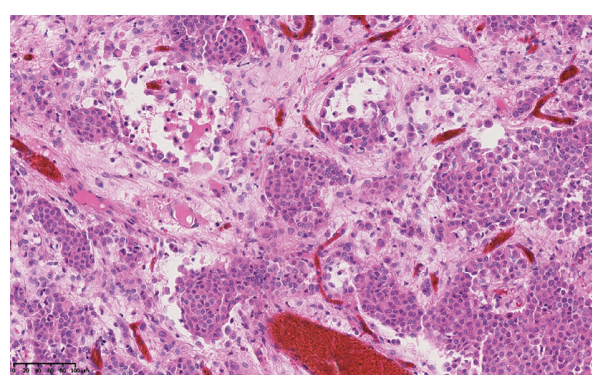

(e)

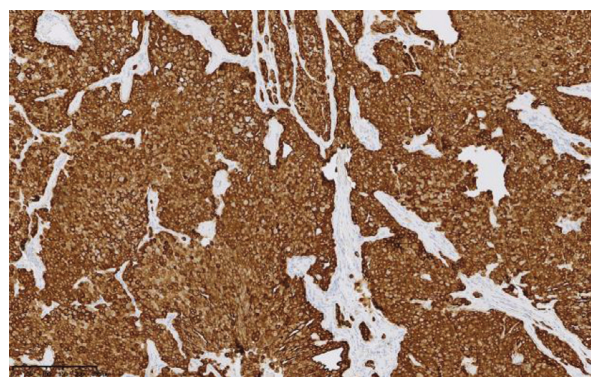

(g)
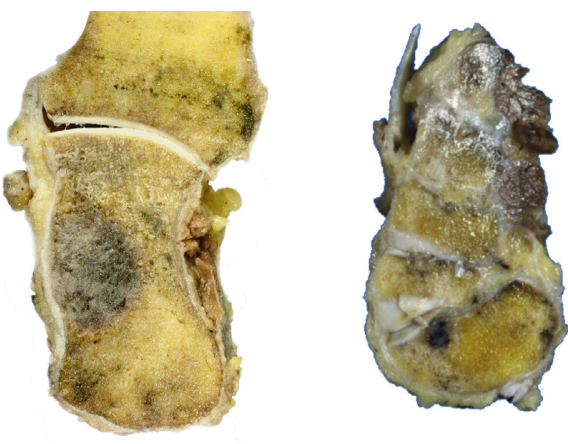

(1) Luแ

(b)

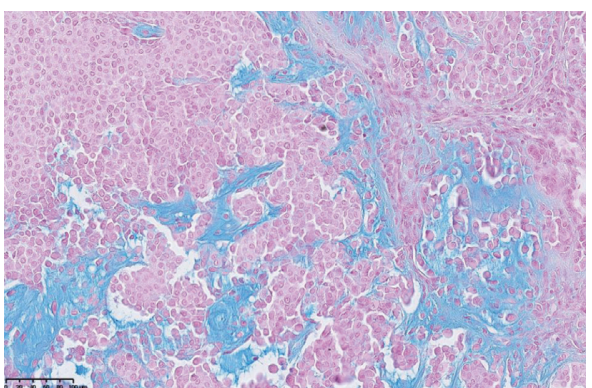

(d)

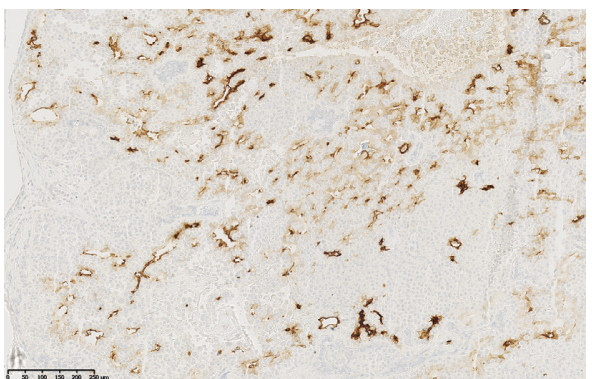

(f)

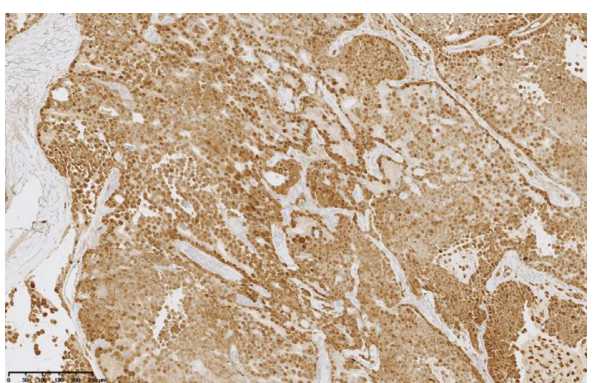

(h)

FIGURE 1: Characterization of the lesions on MRI, macroscopic, microscopic, and immunohistochemical level. (a) MRI gadolinium-enhanced fat-saturated T1-weighted image in the sagittal plane showing an intraosseous lesion of the calcaneus and a plantar soft tissue lesion of the forefoot (arrows). (b) Macroscopic appearance of lesions in the calcaneus and in the cuneiform bone (arrows). (c-e) Lobulated infiltrative pattern made of plasmacytoid cells ( $\mathrm{H}$ and E). (d) Staining of the chondromyxoid stroma by alcian blue. (f-h) Focal expression of the tumor cells for EMA (f), diffuse expression for cytokeratin AE1/AE3 ( $\mathrm{g}$ ), and diffuse expression for S100 protein (h). Sections of bone were performed using the diamond band saw (EXAKT312, Germany) and decalcified with a formamid solution (DC1, V.W.R.) after formalin fixation. $5 \mu \mathrm{m}$ thick sections of the paraffin-embedded material were stained with $\mathrm{H}$ and $\mathrm{E}$ (Symphony 5-Plus, Roche). Immunohistochemistry experiments were performed according to standard procedures. Primary antibodies used on XT benchmark platform (Ventana) were CKAE1/AE3 (cloneAE1/AE3; 1.8 mg/L), EMA (clone E29; $2.4 \mathrm{mg} / \mathrm{L}$ ), protein S100 (rabbit polyclonal; 1/100), GFAP (rabbit polyclonal; 1/500), alpha-smooth muscle actin (clone 1A4; $0.4 \mathrm{mg} / \mathrm{L}$ ), desmin (clone D33; $2.05 \mathrm{mg} / \mathrm{L}$ ), INI1/BAF47 (clone 25/BAF47; $2.5 \mathrm{mg} / \mathrm{L}$ ), and vimentin (clone V9; $0.5 \mathrm{mg} / \mathrm{L}$ ). 


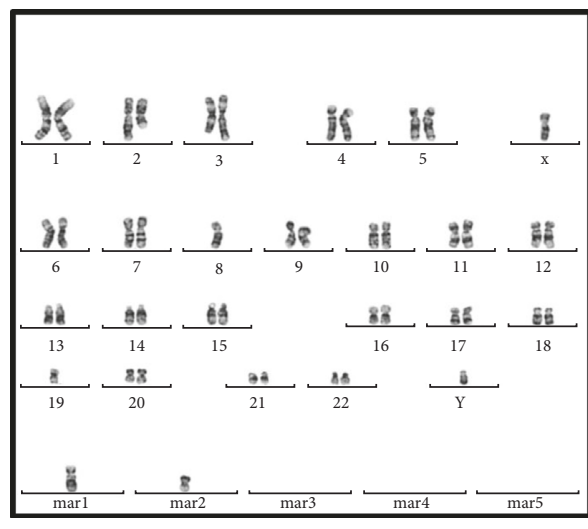

(a)

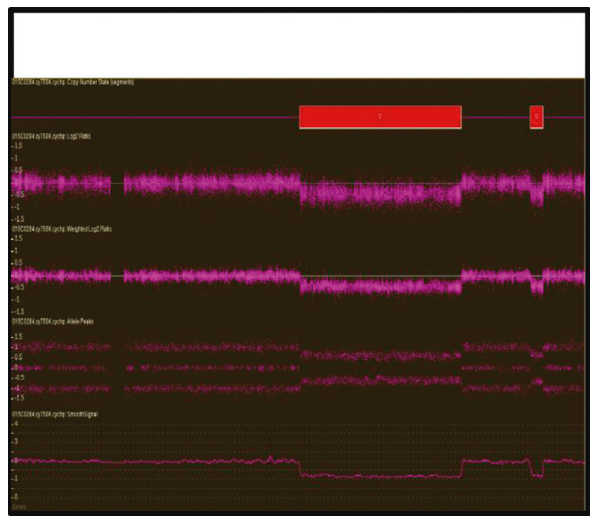

(c)

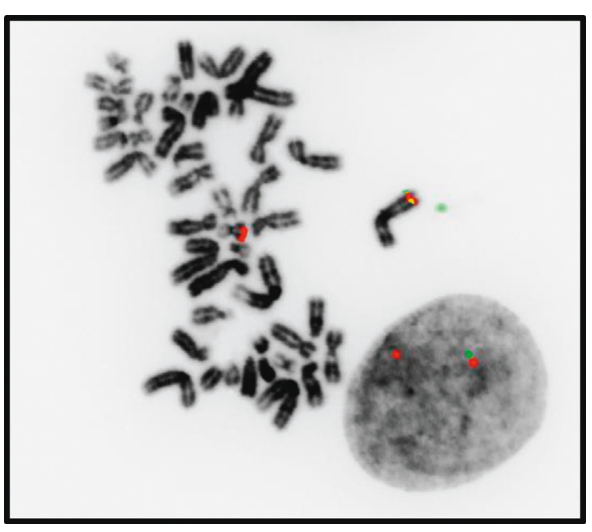

(b)

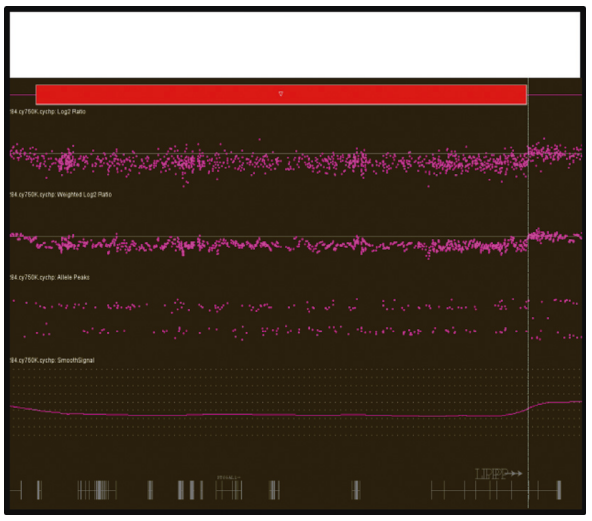

(d)

Figure 2: Cytogenetic characterization. (a) Conventional karyotype on the bone tumor (calcaneum): 46,XY,add(2)(q?21),der(3)t(2;3) (q?21;q?21),-8,-19,+mar1,+mar2[8]. The soft tissue tumor harbor the same chromosomal aberrations: 46,XY, $\operatorname{add}(2)(\mathrm{q} ? 21)$, der(3)t(2;3) (q?21;q?21),-8,-19,+mar1,+mar2[2]. (b) FISH experiments with break-apart probes on fixed cells: deletion of the BAC probe located $5 \%$ centromeric (RP11-1144D2 labelled in green) to the LPP (lipoma preferred partner or LIM Domain Containing Preferred Translocation Partner In Lipoma) locus in a metaphasic cell and in a nucleus (soft tissue tumor): ish der(?)t(3,?)(RP11-1144D2-,RP1167E18-;RP11-67E18+[5].nuc ish(RP11-1144D2x1,RP11-67E18x2)(RP11-1144D2 con RP11-67E18x1)[334/400]. (c, d) Molecular karyotyping (soft tissue tumor): 2 interstitial deletions within the long arm of chromosome 3 (c) and the telomeric one delete the 5 ' part of the $L P P$ locus (d) arr[hg19] 3q22.1q26.2(133,374,187-169,925,119),3q27.2q28(185,628,780-188,411,171)x1. Culturing, harvesting, and G-banding of the tumor samples for karyotyping were performed according to standard procedures [21]. Culturing, harvesting, and G-banding of the tumor samples for karyotyping were performed according to standard procedures [21]. Dual-color FISH experiments were performed on fixed nuclei and on formalin-fixed paraffin-embedded tissue sections ( $4 \mu \mathrm{m}$-thick), using commercial probes (LSIEWSR1, LSI-FUS, LSI-TP53/CEP17, LSI-9p21/CEP9, LSI-TP53/CEP17 from Abbott Molecular/Vysis; ON-TFE3 from Kreatech) and bacterial artificial chromosome (BACs) probes. The BAC clones were purchased from the Chori BACPAC Resources Center (Oakland, USA) to study the following loci: NR4A3/9q31.1 (RP11-412F16, RP11-47M15, RP11-266D8, and RP11-282C24); HMGA2/12q14.3 (RP11317J13, RP11-412I20, RP11-945G8, and RP-347J7); and LPP/3q27.3-q28 (RP11-1144D2 and RP11-67E18). Extraction, labeling, and hybridization were performed, as previously reported [22]. Two hundred interphasic cells and all hybridized metaphases were analysed. Molecular karyotyping was performed with Cytoscan 750K SNP-arrays according to the manufacturer's instructions (Affymetrix). Results were analysed as previously reported [23]. Aberrations greater than $100 \mathrm{~kb}$ involving at least 20 consecutive SNPs were considered for copy number variant (CNV) analysis. Constitutional CNV polymorphisms were excluded based on comparisons with the Database of Genome Variants (hg19). The quality control metrics were within the normal range (SnpQC = 17.656, Mapd =0.195, and Waviness $=0.088$ ).

hematological malignancies: KMT2A(11q23) in a secondary acute leukemia [28] and $B C L 6(3 q 27)$ through a $3 q 27$ interstitial deletion in a primary central nervous system lymphomas [33].

The oncogenic role of $L P P$ remains unclear, while the role of the partner gene seems to be crucial. Several lines of evidence suggest that HMGA2 truncation occurring in the most common $\mathrm{t}(3 ; 12)$ fusion gene is implicated in lipomagenesis.
However, the HMGA2-LPP fusion protein retains the transactivation functions of two LPP LIM domains which might contribute to the mesenchymal tumorigenesis by directly affecting transcriptional regulation processes [34].

In the present case, the suspected breakpoint within the LPP locus suggests that carboxy-terminal LIM transactivating domains may contribute to the chimeric protein with the aminoterminal part of an unidentified gene. 
Although not rearranged by FISH, we cannot exclude a cryptic insertion of the 5' part of HMGA2 within the LPP locus. The only candidate locus for a gene fusion with $L P P$ may be TRPS1 (8q23.3) whose 3' part is deleted. TRPS1 is known to be associated with tumorigenesis, metastasis, and angiogenesis in several tumors, including osteosarcoma [35]. Unfortunately, it was not possible to further characterize the LPP-partner gene by 3' RACE-PCR or RNASeq.

No ductal differentiation was present although membranous EMA staining was focally detected. The stroma was focally myxoid but without a mesenchymal cell population as observed in mixed tumors. Recurrent genetic abnormalities involving PLAG1 and HMGA2 have been described in pleomorphic adenomas (mixed tumors) of salivary gland [36]. PLAG1 rearrangements were mainly identified in a subset of cutaneous and superficial soft tissue MET tumors, often displaying ductal structures and considered as mixed tumors [10]. PLAG1 has not been tested because of the absence of ductular differentiation in the tumor.

We describe here a new rearrangement of the LPP (3q273q28) locus in synchronous tumors presenting epithelioid features. The partner gene remains to be characterized. Analysis of the LPP locus should be performed by FISH on MET without EWSR1 or FUS rearrangements and pleomorphic adenomas of salivary gland without PLAG1 and $H M G A 2$ aberrations to define the recurrence and the tumor characteristics associated with this new alteration.

\section{Ethical Approval}

The study was approved by the local ethics committee.

\section{Conflicts of Interest}

The authors declare that there are no conflicts of interest regarding the publication of this paper.

\section{Acknowledgments}

The authors gratefully acknowledge all the members of the local multidisciplinary oncological committee for sarcoma, Christian Delloye and Filomena Mazzeo for the clinical management of the patient, and Geneviève Ameye for supervising the FISH analyses.

\section{References}

[1] T. Burke, A. Sahin, D. E. Johnson, N. G. Ordóñez, and B. Mackay, "Myoepithelioma of the retroperitoneum," Ultrastructural Pathology, vol. 19, no. 4, pp. 269-274, 1995.

[2] S. E. Kilpatrick, M. G. Hitchcock, M. D. Kraus, E. Calonje, and C. D. Fletcher, "Mixed tumors and myoepitheliomas of soft tissue: a clinicopathologic study of 19 cases with a unifying concept," The American Journal of Surgical, vol. 21, no. 1, pp. 13-22, 1997.

[3] E. Bell, J. J. Van der Biezen, and P. M. N. Werker, "Parachordoma: a very rare tumour of the hand," Journal of Hand Surgery (European Volume), vol. 34, no. 6, pp. 814-816, 2009.

[4] J. S. Park, K. N. Ryu, C. S. Han, and Y. K. Park, "Malignant myoepithelioma of the humerus with a satellite lesion: a case report and literature review," British Journal of Radiology, vol. 83, no. 991, pp. e161-e164, 2010.

[5] V. K. Jain, D. Jain, A. Jawed, A. Prasad, N. Sachdev, and S. Kumar, "Primary myoepithelioma of bone," Pathology, vol. 42, no. 2, pp. 190-193, 2010.

[6] C. D. M. Fletcher, J. A. Bridge, P. C. W. Hogendoorn, and F. Mertens, WHO Classification of Tumors of Soft Tissue and Bone, IARC, Lyon, France, 4th edition, 2013.

[7] A. Verma and B. Rekhi, "Myoepithelial tumor of soft tissue and bone: a current perspective," Histology and Histopathology, vol. 32, no. 9, pp. 861-877, 2017, [Epub ahead of print] Review.

[8] J. L. Hornick and C. D. Fletcher, "Myoepithelial tumors of soft tissue: a clinicopathologic and immunohistochemical study of 101 cases with evaluation of prognostic parameters," The American Journal of Surgical Pathology, vol. 27, no. 9, pp. 1183-1196, 2003.

[9] B. Rekhi, M. Sable, and N. A. Jambhekar, "Histopathological, immunohistochemical and molecular spectrum of myoepithelial tumours of soft tissues," Virchows Archiv, vol. 461, no. 6, pp. 687-697, 2012.

[10] C. R. Antonescu, L. Zhang, N. E. Chang et al., "EWSR1POU5F1 fusion in soft tissue myoepithelial tumors. A molecular analysis of sixty-six cases, including soft tissue, bone, and visceral lesions, showing common involvement of the EWSR1 gene," Genes, Chromosomes and Cancer, vol. 49, no. 12, pp. 1114-1124, 2010.

[11] C. Fisher, "The diversity of soft tissue tumours with EWSR1 gene rearrangements: a review," Histopathology, vol. 64, no. 1, pp. 134-150, 2014.

[12] N. P. Agaram, H. W. Chen, L. Zhang et al., "EWSR1-PBX3: a novel gene fusion in myoepithelial tumors," Genes, Chromosomes and Cancer, vol. 54, no. 2, pp. 63-71, 2015.

[13] P. Brandal, I. Panagopoulos, B. Bjerkehagen et al., "Detection of a $\mathrm{t}(1 ; 22)(\mathrm{q} 23 ; \mathrm{q} 12)$ translocation leading to an EWSR1PBX1 fusion gene in a myoepithelioma," Genes, Chromosomes and Cancer, vol. 47, no. 7, pp. 558-564, 2008.

[14] P. Brandal, I. Panagopoulos, B. Bjerkehagen, and S. Heim, " $\mathrm{t}(19 ; 22)(\mathrm{q} 13 ; \mathrm{q} 12)$ Translocation leading to the novel fusion gene EWSR1-ZNF444 in soft tissue myoepithelial carcinoma," Genes, Chromosomes and Cancer, vol. 48, no. 12, pp. 10511056, 2009.

[15] S. C. Huang, H. W. Chen, L. Zhang et al., "Novel FUS-KLF17 and EWSR1-KLF17 fusions in myoepithelial tumors," Genes, Chromosomes and Cancer, vol. 54, no. 5, pp. 267-275, 2015.

[16] U. Flucke, T. Mentzel, M. A. Verdijk et al., "EWSR1-ATF1 chimeric transcript in a myoepithelial tumor of soft tissue: a case report," Human Pathology, vol. 43, no. 5, pp. 764-768, 2012.

[17] F. Puls, E. Arbajian, L. Magnusson, H. Douis, L. G. Kindblom, and F. Mertens, "Myoepithelioma of bone with a novel FUSPOU5F1 fusion gene," Histopathology, vol. 65, no. 6, pp. 917-922, 2014.

[18] C. Martins, I. Fonseca, L. Roque et al., "PLAG1 gene alterations in salivary gland pleomorphic adenoma and carcinoma ex-pleomorphic adenoma: a combined study using chromosome banding, in situ hybridization and immunocytochemistry," Modern Pathology, vol. 18, no. 8, pp. 1048-1055, 2005.

[19] C. R. Antonescu, L. Zhang, S. Y. Shao et al., "Frequent PLAG1 gene rearrangements in skin and soft tissue myoepithelioma with ductal differentiation," Genes, Chromosomes and Cancer, vol. 52, no. 7, pp. 675-682, 2013. 
[20] A. Bahrami, J. D. Dalton, J. F. Krane, and C. D. Fletcher, "A subset of cutaneous and soft tissue mixed tumors are genetically linked to their salivary gland counterpart," Genes, Chromosomes and Cancer, vol. 51, no. 2, pp. 140-148, 2012.

[21] C. Galant, P.-L. Docquier, G. Ameye, Y. Guiot, J. Malghem, and H. A. Poirel, "Aneurysmal bone cystic lesions: value of genomic studies," Acta Orthopaedica Belgica, vol. 82, no. 4, pp. 768-778, 2016.

[22] F. P. Duhoux, G. Ameye, V. Lambot et al., "Refinement of 1p36 alterations not involving PRDM16 in myeloid and lymphoid malignancies," PLoS One, vol. 6, no. 10, article e26311, 2011.

[23] V. Havelange, X. Pepermans, G. Ameye et al., "Genetic differences between paediatric and adult Burkitt lymphomas," British Journal of Haematology, vol. 173, no. 1, pp. 137-144, 2016.

[24] P. Kurzawa, S. Kattapuram, F. J. Hornicek, C. R. Antonescu, A. E. Rosenberg, and G. P. Nielsen, "Primary myoepithelioma of bone: a report of 8 cases," The American Journal of Surgical Pathology, vol. 37, no. 7, pp. 960-968, 2013.

[25] B. Rekhi, S. S. Desai, A. Gulia, A. Puri, and N. A. Jambhekar, "Intraosseous myoepithelioma: a rare, distinct tumor entity," Indian Journal of Pathology \& Microbiology, vol. 57, no. 2, pp. 269-271, 2014.

[26] B. Rekhi, P. Amare, A. Gulia et al., "Primary intraosseous myoepithelioma arising in the iliac bone and displaying trisomies of 11, 15, 17 with del (16q) and del (22q11)-a rare case report with review of literature," Pathology, Research \& Practice, vol. 207, no. 12, pp. 780-785, 2011.

[27] B. T. Dix, M. J. Hentges, K. R. Saltrick, and U. Krishnamurti, "Cutaneous myoepithelioma in the foot: case report," Foot \& Ankle Specialist, vol. 6, no. 3, pp. 239-241, 2013.

[28] L. Dahéron, A. Veinstein, F. Brizard et al., "Human LPP gene is fused to MLL in a secondary acute leukemia with a $t(3 ; 11)$ (q28;q23)," Genes, Chromosomes and Cancer, vol. 31, no. 4, pp. 382-389, 2001.

[29] M. M. R. Petit, R. Mols, E. F. Schoenmakers, N. Mandahl, and W. J. M. Van de Ven, "LPP, the preferred fusion partner gene of HMGIC in lipomas, is a novel member of the LIM protein gene family," Genomics, vol. 36, no. 1, pp. 118-129, 1996.

[30] I. von Ahsen, P. Rogalla, and J. Bullerdiek, "Expression patterns of the LPP-HMGA2 fusion transcript in pulmonary chondroid hamartomas with $\mathrm{t}(3 ; 12)$ (q27 approximately 28 ; q14 approximately 15)," Cancer Genetics and Cytogenetics, vol. 163, no. 1, pp. 68-70, 2005.

[31] Dahlén A, Mertens F, Rydholm A, Brosjö O, Wejde J, Mandahl $\mathrm{N}$ et al, "Fusion, disruption, and expression of HMGA2 in bone and soft tissue chondromas," Modern Pathology, vol. 16, no. 11, pp. 1132-1140, 2003.

[32] X. Wang, R. Q. Zamolyi, H. Zhang et al., "Fusion of HMGA1 to the LPP/TPRG1 intergenic region in a lipoma identified by mapping paraffin-embedded tissues," Cancer Genetics and Cytogenetics, vol. 196, no. 1, pp. 64-67, 2010.

[33] H. Schwindt, T. Akasaka, R. Zühlke-Jenisch et al., "Chromosomal translocations fusing the BCL6 gene to different partner loci are recurrent in primary central nervous system lymphoma and may be associated with aberrant somatic hypermutation or defective class switch recombination," Journal of Neuropathology \& Experimental Neurology, vol. 65, no. 8, pp. 776-782, 2006.

[34] K. R. Crombez, E. M. Vanoirbeek, W. J. Van de Ven, and M. M. Petit, "Transactivation functions of the tumor-specific HMGA2/LPP fusion protein are augmented by wild-type
HMGA2," Molecular Cancer Research, vol. 3, no. 2, pp. 6370, 2005.

[35] Z. Li, M. Jia, X. Wu, J. Cui, A. Pan, and L. Li, "Overexpression of Trps1 contributes to tumor angiogenesis and poor prognosis of human osteosarcoma," Diagnostic Pathology, vol. 10, no. 1, p. 167, 2015.

[36] F. Persson, Y. Andren, M. Winnes et al., "High-resolution genomic profiling of adenomas and carcinomas of the salivary glands reveals amplification, rearrangement, and fusion of HMGA2," Genes, Chromosomes and Cancer, vol. 48, no. 1, pp. 69-82, 2009. 


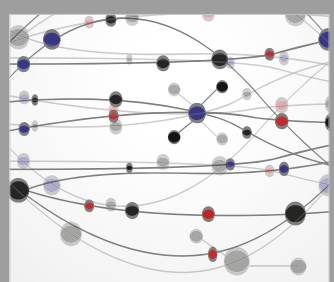

The Scientific World Journal
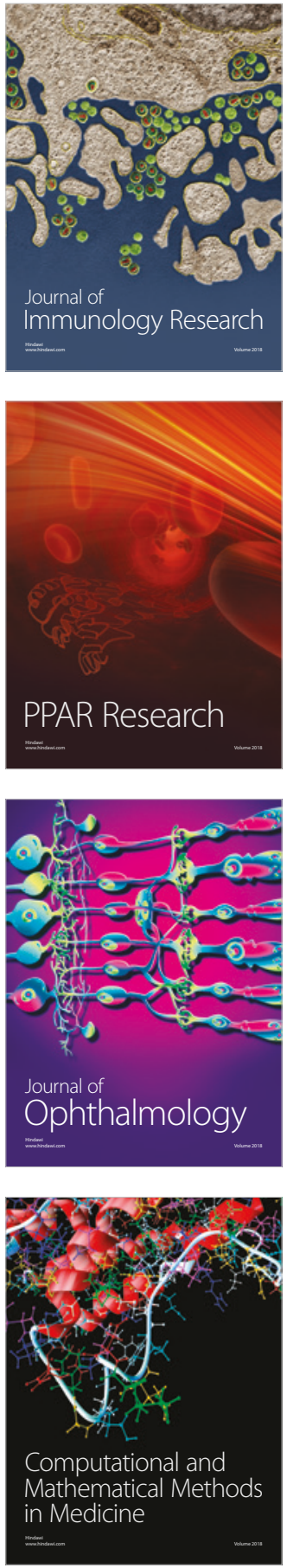

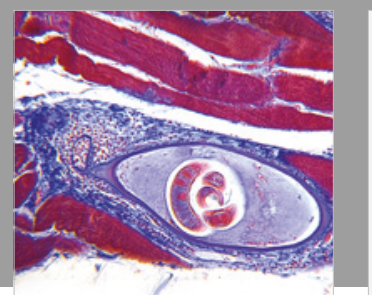

Gastroenterology Research and Practice

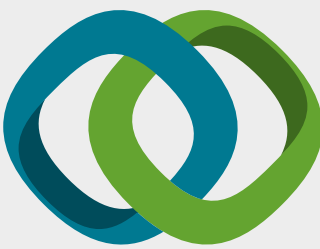

\section{Hindawi}

Submit your manuscripts at

www.hindawi.com
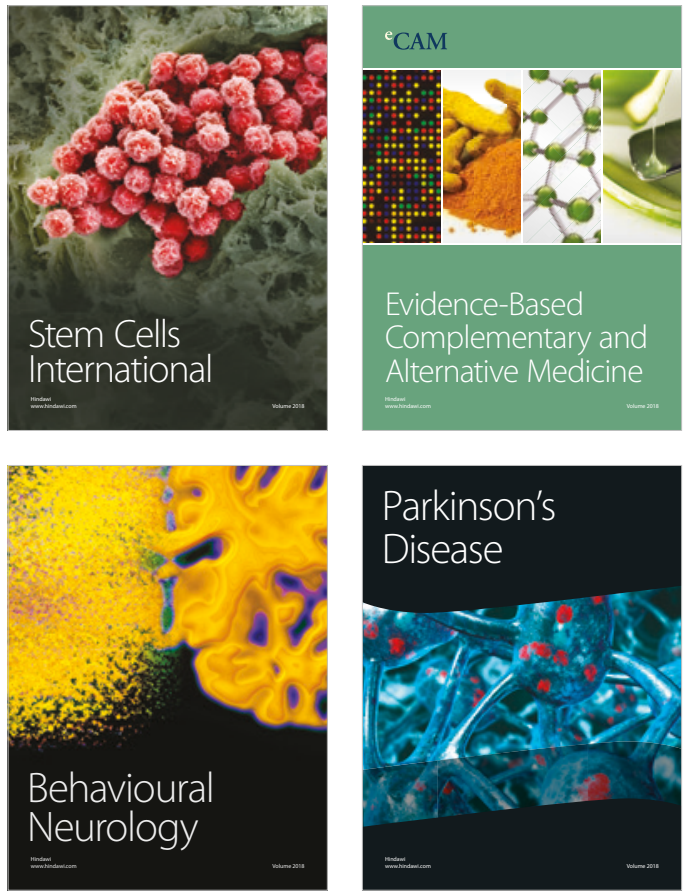

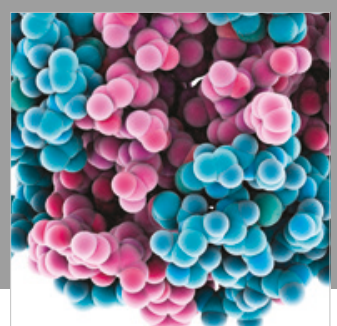

ournal of

Diabetes Research

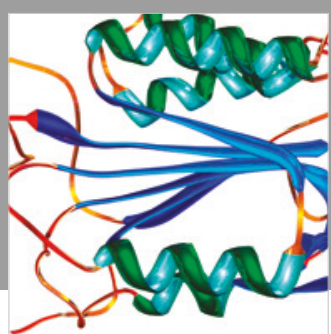

Disease Markers
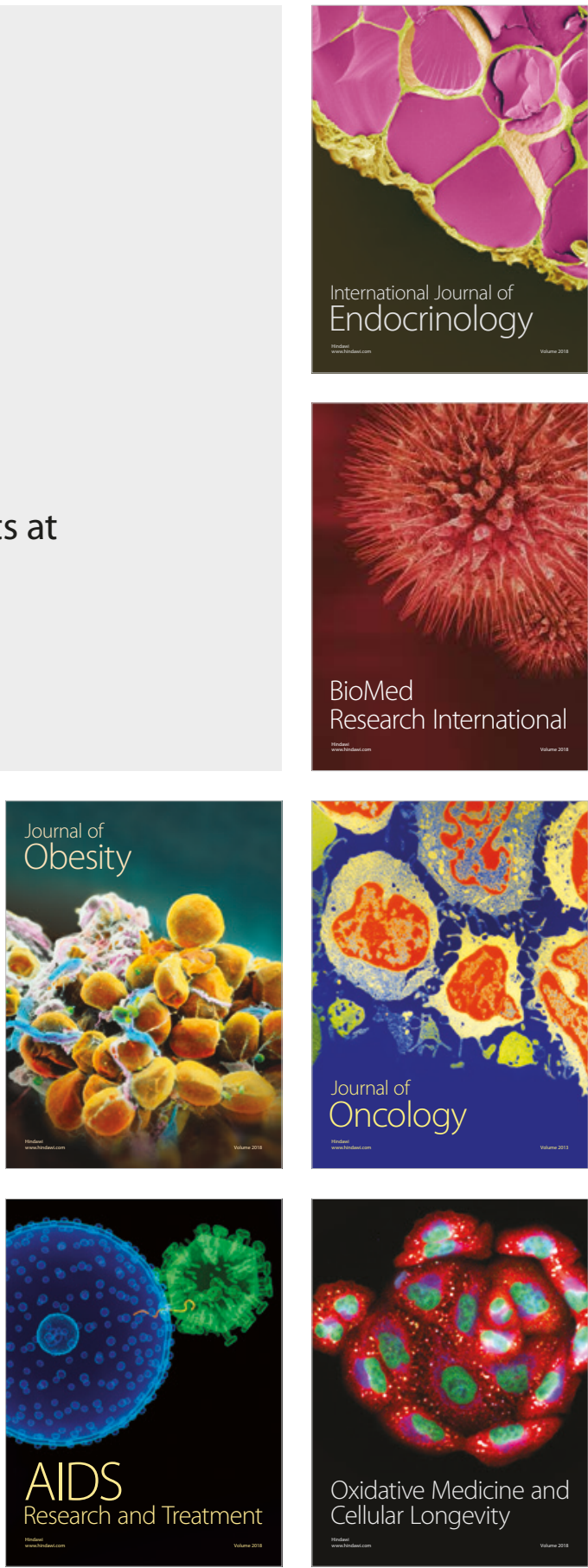